School of Finance

University of St.Gallen

\title{
MOMENTUM AND CRASH SENSITIVITY
}

STEFAN RUENZI

FLORIAN WEIGERT

WORKING PAPERS ON FINANCE NO. 2018/1

SWISS INSTITUTE OF BANKING AND FINANCE (S/BF - HSG)

DECEMBER 2017 


\title{
Momentum and Crash Sensitivity
}

\author{
Stefan Ruenzi and Florian Weigert*
}

This Version: December 2017

\begin{abstract}
This paper proposes a risk-based explanation of the momentum anomaly on equity markets. Regressing the momentum strategy return on the return of a self-financing portfolio going long (short) in stocks with high (low) crash sensitivity in the USA from 1963 to 2012 reduces the momentum effect from a highly statistically significant $11.94 \%$ to an insignificant $1.84 \%$. We find additional supportive out-of sample evidence for our risk-based momentum explanation in a sample of 23 international equity markets.
\end{abstract}

Keywords: Asset pricing, asymmetric dependence, copulas, crash sensitivity, momentum, tail risk

JEL Classification Numbers: C12, G01, G11, G12, G17.

\footnotetext{
*Stefan Ruenzi is from the Department of Finance at the University of Mannheim; address: L9, 1-2, 68131 Mannheim, Germany; telephone: +49-621-181-1640; e-mail: ruenzi@bwl.uni-mannheim.de. Florian Weigert is from the Swiss Institute of Banking and Finance, University of St. Gallen; address: Unterer Graben 21, 9000 St. Gallen, Switzerland; telephone: ++41-71-224-7014; e-mail: florian.weigert@unisg.ch. All errors are
} our own. 


\title{
Momentum and Crash Sensitivity
}

\begin{abstract}
This paper proposes a risk-based explanation of the momentum anomaly on equity markets. Regressing the momentum strategy return on the return of a self-financing portfolio going long (short) in stocks with high (low) crash sensitivity in the USA from 1963 to 2012 reduces the momentum effect from a highly statistically significant $11.94 \%$ to an insignificant $1.84 \%$. We find additional supportive out-of sample evidence for our risk-based momentum explanation in a sample of 23 international equity markets.
\end{abstract}

Keywords: Asset pricing, asymmetric dependence, copulas, crash sensitivity, momentum, tail risk

JEL Classification Numbers: C12, G01, G11, G12, G17. 


\section{Introduction}

The cross-sectional momentum effect is an omnipresent anomaly on financial markets. Jegadeesh and Titman (1993) find that a strategy of buying (selling) stocks that have performed well (poorly) over the past 12 months generates high risk-adjusted future returns on the US stock market. The momentum effect is not unique to the US stock market, but also can be found in other equity markets (Rouwenhorst, 1998, Griffin, Ji, and Martin, 2003, and Chui, Titman, and Wei 2010), country equity indices (Asness, Liew, and Stevens, 1997, and Bhojraj and Swaminathan, 2006), currencies (Kho, 1996, LeBaron, 1999, Okunev and White, 2003, and Menkhof, Sarno, Schmeling, and Schrimpf, 2012), commodities (Erb and Harvey, 2006, and Gorton, Hayashi, and Rouwenhorst, 2013), and across asset classes (Asness, Moskowitz, and Pedersen, 2013).

Although momentum is widely documented on financial markets, there is still an active ongoing debate about its main drivers and determinants. While most studies advocate a behavioral explanation for the effect, i.e., momentum is driven by either overreation or underreaction of investors, recent studies point out the riskiness of momentum strategies. ${ }^{1}$ In particular, Barroso and Santa-Clara (2015) find that momentum strategies display large negative skewness and excess kurtosis, i.e., realizations of higher-order moments that are strongly disliked by investors (see, e.g., Kraus and Litzenberger, 1976, and Fang and Lai, 1997). Similarly, Daniel and Moskowitz (2016) show that momentum strategies can experience large, but infrequent crashes. $^{2}$

Another recent strand of the literature shows that investors dislike (lower) tail sensitive assets (e.g., Kelly and Jiang (2014) and Chabi-Yo, Ruenzi, and Weigert, 2017). Motivated by these recent results, we investigate whether momentum profits are driven by exposure of the momentum strategy to a systematic crash risk factor. Specifically, we regress the momentum portfolio long-short return (UMD) on the return of a self-financing portfolio that buys stocks with high crash sensitivity and sells stocks with low crash sensitivity (CRASH) on the US stock market in the period from 1963 to 2012. The crash sensitivity of individual stocks is measured based on the lower tail dependence of their return time series with the market return time series (see Chabi-Yo, Ruenzi, and Weigert, 2017). Our results indicate that the momentum strategy loads significantly positive on the crash sensitivity factor. While simultaneously controlling for the Fama and French (1993) factors, we show that including

\footnotetext{
${ }^{1}$ Explanation based on underreaction are provided, among others, by Chan, Jegadeesh, and Lakonishok, 1996, Barberis, Shleifer, and Vishny, 1998, Hong and Stein, 1999, and Grinblatt and Han (2005). Overreaction of investors can explain to understand the momentum effect, among others, in De Long, Shleifer, Summers, and Waldmann (1990), and Daniel, Hirshleifer, and Subrahmanyam (1998).

${ }^{2}$ In 1932 , the momentum strategy on the US equity market delievered a $-91.54 \%$ return in just two months. In 2009 , US equity momentum yielded a $-73.42 \%$ return in a three-months period.
} 
the crash sensitivity factor as an explanatory variable for the momentum return reduces its annualized alpha from a statistically significant $11.94 \%$ to an insignificant $1.84 \%$, i.e., a percentage decrease of almost $85 \%$.

As an out-of-sample check we also examine the relationship between the momentum return and the crash sensitivity factor on 23 international equity markets. We find that in 22 countries (i.e., in all countries except of Singapore) momentum loads positively on systematic crash sensitivity with corresponding statistical significance (at least on the 10\% level) in 13 countries. Including the crash sensitivity factor as an explanatory variable in the regression setup lowers the alpha of momentum returns in 22 countries and enhances the adjusted R-square in 20 countries of our international sample.

Overall, our findings show that at least a substantial part of U.S. and international momentum profits represents a risk premium for the exposure of the strategy to systematic crash risk.

\section{Main Variables and Data}

We obtain annual data for US stock market momentum (as well as the Fama and French risk factors) from Kenneth French's webpage. ${ }^{3}$ We display summary statistics for the annualized US momentum return in the period from 1963 to 2012 on the left side of the first row in Table 1. Consistent with the literature, we document that the momentum factor has a high positive annualized return $(8.72 \%)$, but also shows significant negative skewness $(-2.38)$ and excess kurtosis (12.91).

\section{[Insert Table 1 about here]}

Annual data for the US crash sensitivity factor is obtained from Chabi-Yo, Ruenzi, and Weigert (2017). Based on daily return data, the authors estimate an individual stock's lower tail dependence with the market using copula functions and refer to this measure as a stock's crash sensitivity. The crash sensitivity factor is then constructed as the equallyweighted average return of the quintile portfolio of stocks with the highest crash sensitivity minus the average return of the quintile portfolio of stocks with the lowest crash sensitivity. For a detailed explanation of the crash sensitivity estimation approach, we refer the reader to Chabi-Yo, Ruenzi, and Weigert (2017). We display summary statistics for the annualized US crash sensitivity factor return in the period from 1963 to 2012 on the right side of the first row in Table 1.

\footnotetext{
${ }^{3}$ To construct the momentum factor, six value-weighted portfolios are formed based on firm size and past returns (month $t-12$ up to $t-1$ ). The momentum factor is then computed as the average return on the two high past return portfolios minus the average return on the two low past return portfolios.
} 
Finally, we obtain momentum returns (as well as the Fama and French risk factors) and crash sensitivity factors for 23 international stock markets from Asness, Frazzini, and Pedersen (2017) and Weigert (2016). The construction of the international UMD and CRASH factors is very similar to those constructed for the USA and is detailed in the respective papers. We display summary statistics for the annualized momentum returns and crash sensitivity factors in Table 1 (rows 2 to 24). Consistent with the literature, we find that the UMD and CRASH factors are positive in every country in the sample and also statistically significantly different from zero in the majority of them. The sample period for each country starts with the availability of momentum return data in Asness, Frazzini, and Pedersen (2014) or crash sensitivity factor data in Weigert (2016), respectively. The sample period ends in 2012.

\section{Empirical Analysis}

In our basic empirical setup, we regress the annual momentum return on the Fama and French (1993) or the Fama and French (2015) risk factors, respectively. We include the crash sensitivity risk factor as an additional explanatory variable to judge whether momentum is related to crash sensitivity. The exact regression setup is based on annual time-series data and can be specified as follows:

$$
\begin{gathered}
\mathrm{UMD}_{t}=\alpha+\beta_{1} \cdot \mathrm{MKT}-\mathrm{RF}_{t}+\beta_{2} \cdot \mathrm{SMB}_{t}+\beta_{3} \cdot \mathrm{HML}_{t}+ \\
\beta_{4} \cdot \mathrm{RMW}_{t}+\beta_{5} \cdot \mathrm{CMA}_{t}+\beta_{6} \cdot \mathrm{CRASH}_{t}+\epsilon_{t}
\end{gathered}
$$

where $\mathrm{UMD}_{t}$ denotes the momentum factor, $\mathrm{MKT}-\mathrm{RF}_{t}$ denotes the excess market return, $\mathrm{SMB}_{t}$ denotes the Fama and French (1993) small-minus-big size factor, $\mathrm{HML}_{t}$ denotes the Fama and French (1993) high-minus-low book-to-market factor, RMW $W_{t}$ denotes the Fama and French (2015) robust-minus-weak profitability factor, $\mathrm{CMA}_{t}$ denotes the Fama and French (2015) conservative-minus-aggressive investment factor, and $\mathrm{CRASH}_{t}$ denotes the Chabi-Yo, Ruenzi, and Weigert (2017) crash sensitivity factor. T-statistics of alphas and coefficient estimates are computed using Newey and West (1987) standard errors with 2 lags.

[Insert Table 2 about here]

Table 2 displays the results of different specifications of this regression on the US stock market in the period from 1963 to 2012. In specification (1) we regress the momentum 
return on the Fama and French (1993) factors. We confirm that the momentum portfolio delivers a significantly positive annualized alpha which amounts to $11.9 \%$ with a t-statistic of 4.32. In specification (2), we extend the Fama French (1993) three-factor model by the crash sensitivity factor. Our results indicate that the crash sensitivity factor strongly loads on the momentum portfolio with a coefficient estimate of 0.574 and a t-statistic of 5.73. The inclusion of the crash sensitivity factor in the regression model leads the momentum strategy's alpha to drop to $1.84 \%$ per annum, i.e., correcting strategy returns for systematic crash sensitivity reduces profitability by about $85 \%$. The alpha estimate is not statistically different from zero anymore (t-statistic of 0.52 ).

In specifications (3) and (4) we repeat the analysis, but use the Fama and French (2015) five-factor model as our baseline model. ${ }^{4}$ As before, we find that the momentum strategy is highly profitable as long as we do not control for its exposure to systematic crash risk. Including the crash sensitivity factor in the regression model decreases the momentum strategy's alpha from a highly significant $13.2 \%$ to an insignificant $2.9 \%$ per annum.

To obtain additional robustness for our results, we also investigate the relationship between momentum and crash sensitivity on 23 international equity markets. To do so, we regress the country-specific momentum return on the country-specific Fama and French (1993) factors as well as the crash sensitivity factor for the respective country. Results are displayed in Table 3 .

[Insert Table 3 about here]

Column 1 displays the country, while column 2 (4) shows that alpha of the momentum return when controlling for the Fama and French (1993) factors (the Fama and French (1993) factors and the CRASH factor). Column (3) shows the momentum strategy exposure to CRASH. Our results indicate that the crash sensitivity factor loads positively on momentum in 22 out of 23 countries; the coefficient estimate is statistically significant (at least on the $10 \%$ level) in 13 of these countries. The inclusion of the crash sensitivity factor as an explanatory variable in the regression setup lowers the momentum strategy's alpha in 22 countries with an average decrease of $-3 \%$ per annum (Column 5). Moreoever, we find that including crash sensitivity in the regression setup also raises the adjusted R-squared in 20 countries with an average increase of 0.11 (Column 6). Hence, we also find additional out-of sample support that the momentum effect is strongly related to a stock's crash sensitivity. The quantitative magnitude of the reduction is typically smaller than in the U.S.; however, it

\footnotetext{
${ }^{4}$ Results are robust if we use a battery of alternative systematic risk factor models suggested in the literature (and also used in Chabi-Yo, Ruenzi, and Weigert, 2017) or if we use value- instead of equallyweighted returns to construct the CRASH factor.
} 
is still substantial particularly among many of the countries where the momentum strategy delivers significant Fama and French (1993) alphas to start with.

\section{Conclusion}

We find that controlling for the momentum strategy's crash sensitivity reduces its profitability markedly. Our results are in line with the idea that at least a substantial part of the profitability of the momentum effect is a compensation for systematic crash risk exposure. Hence, our results provide a risk-based explanation of the momentum anomaly. This finding does of course not preclude that alternative behavioral explanations also drive a part of the momentum strategy returns. 


\section{References}

Asness, C.; Frazzini, A.; Pedersen, L.H. (2017). "Quality minus junk". Working Paper, AQR Capital Management, Copenhagen Business School, and New York University.

Asness, C.; Liew, J.; Stevens, R. (1997). "Parallels between the cross-sectional predictability of stock and country returns". Journal of Portfolio Management 37, 67-75.

Asness, C.; Moskowitz, T.J.; Pedersen, L. (2013). "Value and momentum everywhere". Journal of Finance 58, 929-986.

Barberis, N.; Shleifer, A.; Vishny, R. (1998). "A model of investor sentiment". Journal of Financial Economics 49, 307-343.

Barroso, P.; Santa-Clara, P. (2015). "Momentum has its moments". Journal of Financial Economics 116, 111-120.

Bhojraj, S.; Swaminathan, B. (2006). "Macromomentum: returns predictability in international equity indices". Journal of Business 79, 429-451.

Chabi-Yo, F.; Ruenzi, S.; Weigert, F. (2017). "Crash sensitivity and the cross-section of expected stock returns". Journal of Financial and Quantitative Analysis, forthcoming.

Chan, L.K.C.; Jegadeesh, N.; Lakonishok, J. (1996). "Momentum strategies". Journal of Finance 51, 1681-1713.

Chui, A.C.W.; Titman, S.; Wei, K.C.J. (2010). "Individualism and momentum around the world". Journal of Finance 65, 361-392.

Daniel, K.; Moskowitz, T.J. (2016). "Momentum crashes". Journal of Financial Economics $122,221-247$.

Daniel, K.; Hirshleifer, D.; Subrahmanyam, A. (1998). "Investor psychology and security market under- and overreactions". Journal of Finance 53, 1839-1885.

DeLong, J.B.; Shleifer, A.; Summers, L.H.; Waldmann, R.J. (1990). "Noise trader risk in financial markets". Journal of Political Economy 98, 703-738.

Erb, C.; Harvey, C. (2006). "The strategic and tactical value of commodity futures". Financial Analysts Journal 62, 69-97.

Fama, E.F.; French, K.R. (1993). "Common risk factors in the returns on stocks and bonds". Journal of Financial Economics 33, 3-56.

Fang, H.; Lai, T-Y. (1997). "Co-kurtosis and capital asset pricing". Financial Review 32, 293-307.

Gorton, G.B.; Hayashi, F.; Rouwenhorst, K. (2013). "The fundamentals of commodity future returns". Review of Finance 17, 35-105. 
Griffin, J.; Ji, X.; Martin, J. (2003). "Momentum investing and business cycle risk: evidence from pole to pole". Journal of Finance 53, 2515-2546.

Grinblatt, M.; Han, B. (2005). "Prospect theory, mental accounting, and momentum". Journal of Financial Economics 78, 311-339.

Hong, H.; Stein, J.C. (1999). "A unified theory of underreaction, momentum trading, and overreaction in asset markets". Journal of Finance 54, 2143-2184.

Jegadeesh, N.; Titman, S. (1993). "Returns to buying winners and selling losers: implications for stock market efficiency". Journal of Finance 48, 65-91.

Kelly, B.; Jiang, H. (2014). "Tail risk and asset prices". Review of Financial Studies 27, 2841-2871.

Kraus, A.; Litzenberger, R.H. (1976). "Skewness preference and the valuation of risk assets". Journal of Finance 31, 1085-1100.

Kho, B.C. (1996). "Time-varying risk premia, volatility, and technical trading rule profits: evidence from foreign currency future markets". Journal of Financial Economics 41, 249 290.

LeBaron, B. (1999). "Technical trading rule profitability and foreign exchange intervention". Journal of International Economics 49, 125-143.

Menkhoff, L.; Sarno, L.; Schmeling, M.; Schrimpf, A. (2012). "Currency momentum strategies". Journal of Financial Economics 106, 620-684.

Newey, W.K.; West, K.D. (1987). "A simple positive semi-definite, heteroskedasticity and autocorrelation consistent covariance matrix". Econometrica 55, 703-708.

Okunev, J.; White, D. (2003). "Do momentum-based strategies still work in foreign currency markets?". Journal of Financial and Quantitative Analysis 38, 425-447.

Rouwenhorst, K. (1998). "International momentum strategies". Journal of Finance 53, 14391464.

Weigert, F. (2016). "Crash aversion and the cross-section of expected stock returns worldwide". Review of Asset Pricing Studies 6, 135-178. 


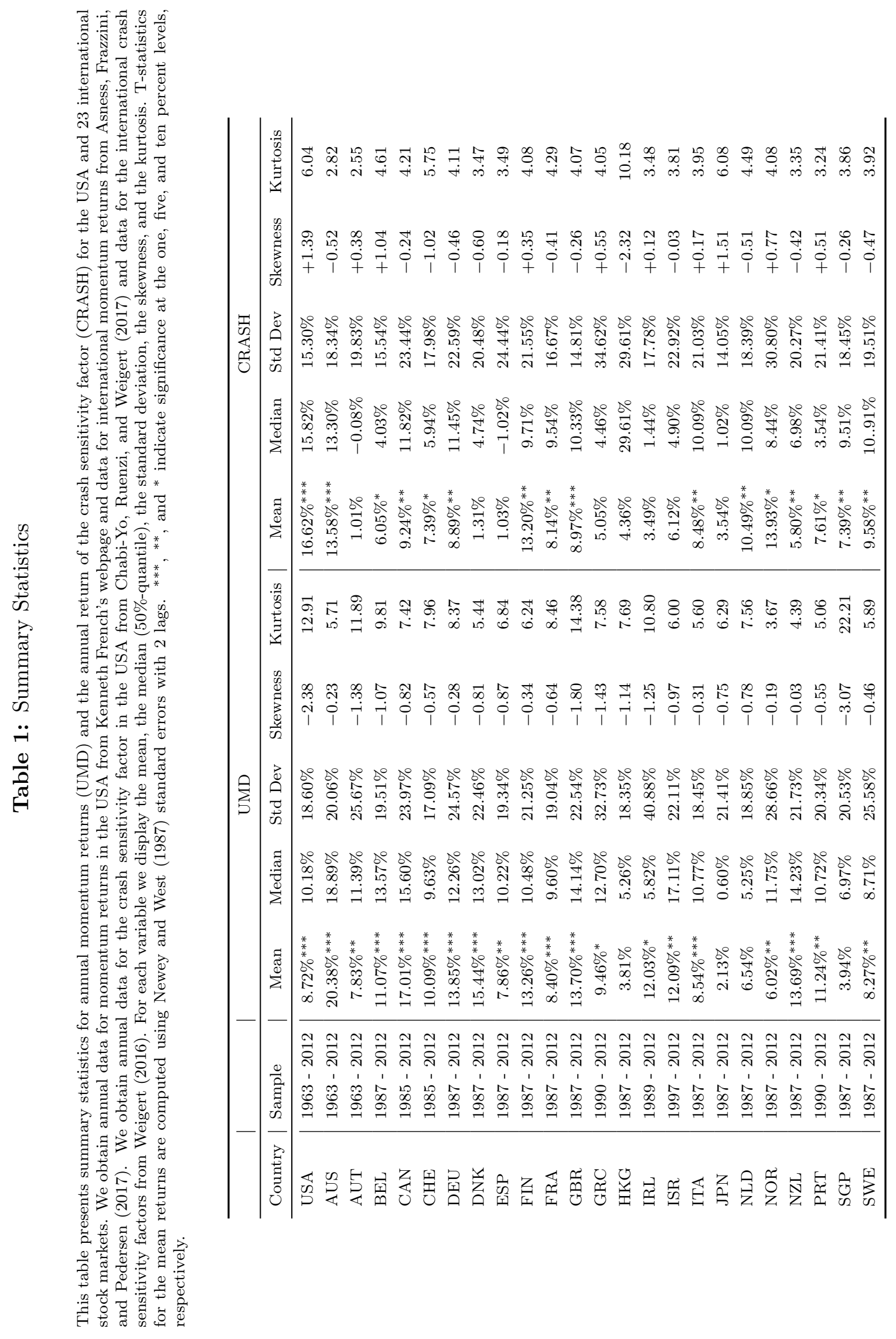


Table 2: Momentum and Crash Sensitivty: US Evidence

This table shows the results of time-series regressions of the following form:

$$
\begin{aligned}
& \mathrm{UMD}_{t}=\alpha+\beta_{1} \cdot \mathrm{MKT}_{-\mathrm{RF}}+\beta_{2} \cdot \mathrm{SMB}_{t}+\beta_{3} \cdot \mathrm{HML}_{t}+ \\
& \beta_{4} \cdot \mathrm{RMW}_{t}+\beta_{5} \cdot \mathrm{CMA}_{t}+\beta_{6} \cdot \mathrm{CRASH}_{t}+\epsilon_{t},
\end{aligned}
$$

where $\mathrm{UMD}_{t}$ denotes the momentum factor, $\mathrm{MKT}-\mathrm{RF}_{t}$ denotes the excess market return, $\mathrm{SMB}_{t}$ denotes the Fama and French (1993) small-minus-big size factor, $\mathrm{HML}_{t}$ denotes the Fama and French (1993) high-minuslow book-to-market factor, $\mathrm{RMW}_{t}$ denotes the Fama and French (2015) robust-minus-weak profitability factor, $\mathrm{CMA}_{t}$ denotes the Fama and French (2015) conservative-minus-aggressive investment factor, and $\mathrm{CRASH}_{t}$ denotes the Chabi-Yo, Ruenzi, and Weigert (2017) crash sensitivity factor. The sample covers the US stock market and the sample period is from 1963 to 2012. T-statistics are in parentheses and are computed using Newey and West (1987) standard errors with 2 lags. ${ }^{* * *},{ }^{* *}$, and ${ }^{*}$ indicate significance at the one, five, and ten percent levels, respectively.

\begin{tabular}{ccccc}
\hline & $(1)$ & $(2)$ & $(3)$ & $(4)$ \\
& UMD & UMD & UMD & UMD \\
\hline MARKETRF & -0.213 & $-0.400^{* *}$ & -0.273 & $-0.419^{* *}$ \\
& $(-1.52)$ & $(-2.54)$ & $(-1.51)$ & $(-2.20)$ \\
SMB & -0.102 & -0.144 & -0.109 & -0.138 \\
& $(-0.65)$ & $(-1.20)$ & $(-0.75)$ & $(-1.09)$ \\
HML & -0.289 & 0.055 & -0.107 & 0.123 \\
& $(-1.64)$ & $(0.27)$ & $(-0.33)$ & $(0.38)$ \\
RMW & & & -0.102 & -0.062 \\
& & & $(-0.40)$ & $(-0.27)$ \\
CMA & & & -0.368 & -0.148 \\
& & & $(-0.97)$ & $(-0.39)$ \\
CRASH & & $0.574^{* * *}$ & & $0.547^{* * *}$ \\
& & $(5.73)$ & & $(4.81)$ \\
Alpha & $0.119^{* * *}$ & 0.018 & $0.132^{* * *}$ & 0.029 \\
& $(4.32)$ & $(0.52)$ & $(5.95)$ & $(0.91)$ \\
\hline Observations & 50 & 50 & 49 & 49 \\
$R^{2}$ & 0.08 & 0.18 & 0.10 & 0.18 \\
\hline
\end{tabular}


Table 3: Momentum and Crash Sensitivty: International Evidence

This table presents results of the relationship between momentum (UMD) and crash sensitivity (CRASH) on 23 international equity markets. We regress the country-specific momentum return on the country-specific Fama and French (1993) factors as well as the crash sensitivity factor for the respective country. Column 1 displays the country, while column 2 (4) shows that alpha of the momentum return when controlling for the Fama and French (1993) factors (the Fama and French (1993) factors and the CRASH factor). Column (3) shows the momentum strategy exposure to CRASH. Column (5) displays the change in the momentum strategy's alphas when controlling for the CRASH factor. Column (6) denotes the number of annual returns in the respective regression. Column (7) reports the change in the adjusted R-squared when controlling for the CRASH factor in the regression. T-statistics are in parentheses and are computed using Newey and West (1987) standard errors with 2 lags. ${ }^{* * *},{ }^{* *}$, and ${ }^{*}$ indicate significance at the one, five, and ten percent levels, respectively.

\begin{tabular}{|c|c|c|c|c|c|c|}
\hline Country & $\begin{array}{c}\text { 3-Factor Alpha } \\
\text { Alpha }\end{array}$ & CRASH & $\begin{array}{c}\text { 4-Factor Alpha } \\
\text { with CRASH }\end{array}$ & $\begin{array}{c}\text { Change in } \\
\text { Alphas }\end{array}$ & Observations & $\begin{array}{c}\text { Change in } \\
\text { Adjusted R-squares }\end{array}$ \\
\hline AUS & $\begin{array}{c}0.179^{* *} \\
(2.74)\end{array}$ & $\begin{array}{c}0.331^{*} \\
(1.82)\end{array}$ & $\begin{array}{l}0.124^{*} \\
(1.78)\end{array}$ & -0.055 & 26 & +0.064 \\
\hline AUT & $\begin{array}{c}0.092^{*} \\
(1.75)\end{array}$ & $\begin{array}{c}0.739^{* *} \\
(2.82)\end{array}$ & $\begin{array}{l}0.049 \\
(1.07)\end{array}$ & -0.043 & 26 & +0.307 \\
\hline BEL & $\begin{array}{c}0.176^{* * *} \\
(6.12)\end{array}$ & $\begin{array}{l}0.276 \\
(0.97)\end{array}$ & $\begin{array}{c}0.162^{* * *} \\
(4.49)\end{array}$ & -0.014 & 26 & +0.031 \\
\hline CAN & $\begin{array}{c}0.141^{* * *} \\
(3.89)\end{array}$ & $\begin{array}{c}0.514^{* *} \\
(2.53)\end{array}$ & $\begin{array}{l}0.073 \\
(1.15)\end{array}$ & -0.068 & 28 & +0.202 \\
\hline $\mathrm{CHE}$ & $\begin{array}{c}0.095^{* * *} \\
(3.02)\end{array}$ & $\begin{array}{l}0.163 \\
(0.64)\end{array}$ & $\begin{array}{c}0.082^{* *} \\
(2.03)\end{array}$ & -0.013 & 26 & +0.028 \\
\hline DEU & $\begin{array}{c}0.134^{* *} \\
(2.53)\end{array}$ & $\begin{array}{l}0.408^{*} \\
(1.75)\end{array}$ & $\begin{array}{c}0.094^{* *} \\
(2.11)\end{array}$ & -0.040 & 26 & +0.140 \\
\hline DNK & $\begin{array}{c}0.203^{* * *} \\
(4.89)\end{array}$ & $\begin{array}{l}0.090 \\
(0.22)\end{array}$ & $\begin{array}{c}0.202^{* * *} \\
(4.80)\end{array}$ & -0.001 & 26 & -0.047 \\
\hline ESP & $\begin{array}{l}0.087 \\
(1.58)\end{array}$ & $\begin{array}{l}0.278 \\
(1.26)\end{array}$ & $\begin{array}{l}0.078 \\
(1.43)\end{array}$ & -0.009 & 26 & +0.075 \\
\hline FIN & $\begin{array}{l}0.073 \\
(1.35)\end{array}$ & $\begin{array}{c}0.535^{* * *} \\
(3.48)\end{array}$ & $\begin{array}{l}0.036 \\
(0.90)\end{array}$ & -0.037 & 26 & +0.183 \\
\hline FRA & $\begin{array}{c}0.126^{* * *} \\
(3.40)\end{array}$ & $\begin{array}{c}0.656^{* * *} \\
(3.72)\end{array}$ & $\begin{array}{c}0.091^{* *} \\
(2.43)\end{array}$ & -0.035 & 26 & +0.292 \\
\hline GBR & $\begin{array}{c}0.160^{* * *} \\
(3.92)\end{array}$ & $\begin{array}{c}0.540^{* *} \\
(2.03)\end{array}$ & $\begin{array}{c}0.119^{*} \\
(2.00)\end{array}$ & -0.041 & 26 & +0.067 \\
\hline GRC & $\begin{array}{l}0.113 \\
(1.30)\end{array}$ & $\begin{array}{l}0.398 \\
(0.85)\end{array}$ & $\begin{array}{l}0.110 \\
(1.23)\end{array}$ & -0.003 & 23 & +0.032 \\
\hline HKG & $\begin{array}{l}0.034 \\
(0.95)\end{array}$ & $\begin{array}{l}0.087 \\
(1.23)\end{array}$ & $\begin{array}{l}0.029 \\
(0.90)\end{array}$ & -0.005 & 26 & +0.021 \\
\hline IRL & $\begin{array}{c}0.194^{* *} \\
(2.54)\end{array}$ & $\begin{array}{l}0.553^{*} \\
(1.75)\end{array}$ & $\begin{array}{r}0.152^{*} \\
(2.01)\end{array}$ & -0.042 & 24 & +0.040 \\
\hline ISR & $\begin{array}{c}0.166^{* * *} \\
(4.18)\end{array}$ & $\begin{array}{l}0.228 \\
(0.81)\end{array}$ & $\begin{array}{c}0.137^{* *} \\
(2.20)\end{array}$ & -0.029 & 16 & +0.000 \\
\hline ITA & $\begin{array}{c}0.102^{* * *} \\
(2.94)\end{array}$ & $\begin{array}{c}0.509^{* * *} \\
(4.42)\end{array}$ & $\begin{array}{r}0.046^{*} \\
(1.79)\end{array}$ & -0.056 & 26 & +0.344 \\
\hline JPN & $\begin{array}{c}0.083^{*} \\
(1.86)\end{array}$ & $\begin{array}{l}0.123 \\
(0.57)\end{array}$ & $\begin{array}{l}0.084^{*} \\
(1.97)\end{array}$ & +0.001 & 26 & -0.043 \\
\hline NLD & $\begin{array}{c}0.089^{*} \\
(1.93)\end{array}$ & $\begin{array}{c}0.443^{* * *} \\
(3.18)\end{array}$ & $\begin{array}{l}0.028 \\
(0.65)\end{array}$ & -0.061 & 26 & +0.146 \\
\hline NOR & $\begin{array}{c}0.140^{* *} \\
(2.54)\end{array}$ & $\begin{array}{c}0.312^{*} \\
(1.99)\end{array}$ & $\begin{array}{c}0.112^{*} \\
(1.84)\end{array}$ & -0.028 & 26 & +0.088 \\
\hline NZL & $\begin{array}{c}0.175^{* * *} \\
(4.73)\end{array}$ & $\begin{array}{c}0.651^{* * * *} \\
(3.02)\end{array}$ & $\begin{array}{c}0.136^{* * *} \\
(3.86)\end{array}$ & -0.039 & 26 & +0.372 \\
\hline PRT & $\begin{array}{c}0.082^{* *} \\
(2.14)\end{array}$ & $\begin{array}{l}0.248 \\
(1.29)\end{array}$ & $\begin{array}{c}0.080^{*} \\
(1.78)\end{array}$ & -0.002 & 23 & +0.009 \\
\hline SGP & $\begin{array}{l}0.005 \\
(0.08)\end{array}$ & $\begin{array}{l}-0.059 \\
(-0.26)\end{array}$ & $\begin{array}{l}0.004 \\
(0.07)\end{array}$ & -0.001 & 26 & -0.043 \\
\hline SWE & $\begin{array}{l}0.013 \\
(0.28)\end{array}$ & $\begin{array}{c}0.662^{* * *} \\
(3.77)\end{array}$ & $\begin{array}{l}-0.052 \\
(-1.20)\end{array}$ & -0.065 & 26 & +0.132 \\
\hline Average & 0.116 & 0.378 & 0.086 & -0.030 & 25.30 & +0.110 \\
\hline
\end{tabular}

